\title{
A cross sectional study to determine utility of childbirth fear screening in maternity practice - an Australian perspective
}

\section{Authors}

Toohill J. ${ }^{1,}$ RN RM PhD Researcher/Lecturer Griffith Health Institute, School of Nursing \& Midwifery, Griffith University. J.Toohill@griffith.edu.au

Creedy DK. ${ }^{1 .}$ RN PhD Professor of Perinatal Mental Health, Griffith Health Institute Griffith University. D.Creedy@griffith.edu.au

Gamble J. ${ }^{1 .}$ RM PhD Professor of Midwifery, Griffith Health Institute, Griffith University. J.Gamble@griffith.edu.au

Fenwick J. ${ }^{1,2}$ RM PhD Professor of Midwifery, Griffith Health Institute, School of Nursing \& Midwifery \& Gold Coast University Hospital J.Fenwick@griffith.edu.au

\section{Corresponding author:}

Jocelyn Toohill

School of Nursing \& Midwifery

Griffith University, Logan Campus

University Drive

Meadowbrook. QLD 4131

Phone +61 (0)7 33821107

Fax $\quad+61(0) 733821277$

Email: J.Toohill@griffith.edu.au

${ }^{1}$ Menzies Health Institute Queensland, Griffith University, University Drive, Meadowbrook, QLD 4131, Australia

${ }^{2}$ Gold Coast University Hospital, Parklands Drive, Southport, QLD 4215, Australia 


\section{Abstract}

Background: Low intensity anxiety in pregnancy is normal however high levels of fear affect between $20-25 \%$ of women, with around $10 \%$ suffering severe levels. Research from Scandinavian countries includes women with severe levels of fear, with little work undertaken in Australia. This paper explores predictors of fear and the relative benefits of screening women for childbirth fear at high or severe levels.

Method: A secondary analysis of data collected for the BELIEF study was conducted to determine differences for demographic, psycho-social and obstetric factors in women with severe fear $(W-D E Q \geq 85, n=68)$ compared to women with less or no fear $(n=1318)$. Women with severe fear $(W-D E Q \geq 85, n=68)$ were also compared to those with high fear scores $(\mathrm{W}-\mathrm{DEQ} \geq 66$ to $84, \mathrm{n}=265)$. Logistic regression modelling was used to ascertain if screening for high or severe levels of fear is most optimal.

Results: 1386 women completed the W-DEQ. There were no differences on demographic variables between women with severe or high fear. Depression symptoms, decisional conflict and low self-efficacy predicted high and severe fear levels. Nulliparity was a predictor of high fear. A previous operative birth and having an unsupportive partner were predictors of high fear in multiparous women.

Conclusion: Psychosocial factors were associated with both high and severe fear levels. Screening for severe fear may detect women with pre-existing mental health problems that are exacerbated by fear of birth. Australian women with high childbirth fear levels (W-DEQ 266) should be identified and provided appropriate support.

Keywords: childbirth fear, W-DEQ, antenatal screening, caesarean section, depression, decisional conflict, self-efficacy, tocophobia 


\section{A cross sectional study to determine utility of childbirth fear screening in maternity practice - an Australian perspective}

\section{Introduction}

Predictors and birth outcomes of women with childbirth fear are of increasing interest in developed countries ${ }^{1-5}$. Predominantly research on childbirth fear has emanated from Scandinavian countries ${ }^{5-7}$. The Wijma Delivery Expectancy Questionnaire $(W-D E Q){ }^{8}$, the most widely used tool to measure childbirth fear, originally delineated women with high fear scores $(\mathrm{W}-\mathrm{DEQ} \geq 66)$ from the rest of the population ${ }^{9}$. Recently severe fear levels (W-DEQ $\geq 85$ ) have become the research focus ${ }^{1,10,11}$. There have been no published studies specific to severe childbirth fear levels in Australian women. The relative benefit of screening women for childbirth fear and making a distinction at the high or severe level is unclear.

The relationship between anxiety and childbirth fear is also unclear. The terms 'childbirth fear' and 'anxiety' are sometimes used interchangeably to describe women's antenatal distress. This may possibly be due to a reported association between anxiety and childbirth fear ${ }^{12-14}$. However comparing anxiety levels to fear in pregnancy is not clear as studies use either general language descriptors or standardised tools developed for the general community or may use measures specific to the childbearing period. Depending on the woman's stage of pregnancy the prevalence of both anxiety and fear levels differ for similar reasons of measurement, but also possibly due to women's initial concerns of viability in early pregnancy having resolved by later trimesters ${ }^{12,15}$. While both anxiety and fear during pregnancy are associated with a history of mental illness, anxiety has not been found to be associated with obstetric history whereas childbirth fear is linked to both adverse personal experience and negative stories of other women ${ }^{12,16,17}$. Therefore while anxiety and fear in pregnancy may be similar, they may not be the same. Whether this remains true for women 
with severe levels of childbirth fear (tocophobia) ${ }^{18}$ is not known, but higher levels of anxiety are predictive of higher levels of childbirth fear and vice versa ${ }^{12,14}$.

This paper reports on a secondary analysis of data collected from women recruited during their second trimester of pregnancy for a randomised controlled trial on childbirth fear known as BELIEF (Birth Emotions and Looking to Improve Expectant Fear) ${ }^{19,20}$. Baseline details for the 1410 women recruited to the study ${ }^{4}$, and outcomes of the intervention ${ }^{20}$ have been published. The prevalence of high fear was $24 \%(n=333)$. The published primary analysis reported significant differences between women scoring high for childbirth fear (W-DEQ $\geq 66$ ) compared to those that did not ${ }^{4}$. In this secondary analysis women's W-DEQ scores were categorised as high fear $(\mathrm{W}-\mathrm{DEQ} \geq 66)$ and severe fear (W-DEQ $\geq 85)$. Demographic, psycho-social factors and birth outcomes of these groups were compared to ascertain predictors of fear levels and relative benefits of screening women for childbirth fear at high or severe levels. Identifying important differences in fear levels could guide clinical practice and optimise utilisation of health resources.

\section{Background}

High childbirth fear is reported to occur for around $20 \%$ to $25 \%$ of women, with severe fear levels impacting $4 \%$ to $16 \%$ of the population $2,4,11,18,21,22$. While variations exist, women having a first baby report higher prevalence and intensity of childbirth fear compared to multiparous women ${ }^{1,4,11}$. However, multiparous women who have experienced an operative birth (more commonly emergency caesarean section) are at risk for childbirth fear and trauma symptoms 11, 16, 23-25. Reports of the contribution of women's demographic backgrounds and birth outcomes associated with childbirth fear also vary ${ }^{18,26-28}$. However fearful women have been shown to have longer labours and high rates of emergency CS. This finding highlights the need for clinicians to consider how they support women to achieve vaginal birth $^{7,21,24}$ and reduce intrapartum caesarean section (CS). 
Having a history of mental health problems and diminished social support has been consistently associated with severe levels of childbirth fear 3, 16, 29-31. Psycho-education interventions provided by midwives ${ }^{20,32}$, obstetricians, or psychologists ${ }^{10,33,34}$ have shown benefit and indicate that childbirth fear is modifiable. Severe levels of fear are considered to be of clinical significance as these women are more likely to seek an elective $\operatorname{CS}^{6,11,28,33,35-}$ ${ }^{37}$ or to experience an emergency $\mathrm{CS}^{7,38-40}$. However one Swedish study found that up to $25 \%$ of women reported their fear was related to the uncertainty of requiring an operative birth ${ }^{41}$. An important reason for maternal requests for CS in the UK was childbirth fear ${ }^{37}$ and fear accounted for $8 \%$ of requests for caesarean sections in Sweden ${ }^{42,}{ }^{43}$. However given differences in culture and provision of maternity services the relevance of international findings of severe childbirth fear to an Australian population is unknown. This paper examines the impact of demographic, psycho-social and obstetric factors on women's birth outcomes at different levels of childbirth fear and the relative benefits of screening women for childbirth fear at high or severe levels..

\section{Method}

Participants were recruited in their second trimester of pregnancy from three maternity hospitals in south east Queensland. Informed written consent was gained from all participants ${ }^{19}$. Women who required an interpreter, those unable to consent or younger than 16 years of age were excluded. Ethics approval was received from Griffith University and the Gold Coast University Hospital, Redlands and Logan Hospitals.

All women invited to the BELIEF study, were screened for childbirth fear using the antenatal Wijma Delivery Expectancy Questionnaire (W-DEQ). At six weeks postnatal the Wijma Delivery Experience Questionnaire (W-DEQB) was used (Refer Box 1). Recruitment occurred from May 2012 to June 2013. Demographic, obstetric history and psycho-social measures were also collected at baseline. Women who reported high childbirth fear (W-DEQ 266) were randomised to the primary (BELIEF) study. These women completed additional 
questionnaires at 36 weeks of pregnancy and at 6 weeks postnatal. Details have been published in the study protocol ${ }^{19}$. Baseline questionnaires could be completed in the antenatal clinic at time of recruitment or mailed to the research office. Subsequent questionnaires were completed by mail or over the telephone with a research assistant who was not a midwife and not involved in any other aspect of the study.

The secondary analysis reported in this current paper is a cross-sectional analysis of participants' data who were recruited to the BELIEF study. The analysis was undertaken to determine whether the 68 women with severe fear $(W-D E Q \geq 85)$ at baseline were different on demographic, psycho-social and obstetric factors compared to women without this level of fear $(n=1318)$. The 265 women with fear scores between 66 and 84 were also compared to those with severe fear to ascertain optimal levels of screening.

In addition, the baseline data for women randomised to the BELIEF study were then analysed against fear scores collected postnatally. Only women who were randomised to the main BELIEF study could return data following birth. There were 139 responses from women reporting high fear, and 41 women reporting severe fear levels.

Descriptive statistics were performed on all data. Demographic variables for country of birth, $\mathrm{BMI}</ \geq 30$, income, paid employment, planned pregnancy, education level, supportive partner, residing with partner, level of discomfort or pain in pregnancy, and perceived childbirth knowledge compared to peers were analysed as dichotomous variables. Smoking status was collected at 36 weeks gestation. Age was a continuous variable. For obstetric variables, weeks of gestation were a continuous variable and all other obstetric variables (birth preference, parity, and operative birth last pregnancy - for multiparous women) were dichotomous. Psycho-social measures for depressive symptoms (EPDS), decisional conflict (DCS), childbirth confidence (CBSEI) and parenting confidence (PSOC) were continuous variables (Refer Box 1). Women's second trimester W-DEQ fear scores were tested as the 
dependent variable by comparing women with or without severe fear $(\mathrm{W}-\mathrm{DEQ}</ \geq 85)$; and comparing women with high versus severe fear scores ( $\geq 66$ to 84 vs $\geq 85$ ). Statistical tests were Mann-Whitney $U$ test and Chi square with Yates Continuity Correction. Logistic regression was conducted to determine predictors for the different levels of childbirth fear compared to women with low or medium fear using cut points of high fear (W-DEQ $\geq 66$ ) and severe fear scores (W-DEQ $\geq 85$ ). Variables used in the logistic regression analysis were drawn from those showing a significant difference against levels of fear and included the additional variables of unsupportive partner and last mode of birth as these are commonly reported in the literature as contributing to childbirth fear. The IBM Statistical Package SPSS $21^{44}$ was used. An alpha level of 0.05 and $95 \%$ confidence interval was used for all statistical tests.

\section{Findings}

Two thousand three hundred and eleven $(n=2311)$ eligible women were approached to participate with 1410 (61\%) returning questionnaires in second trimester. Of these, 1386 (98.3\%) completed the W-DEQ allowing analysis. The population included nulliparous women $(n=604,44 \%)$ and multiparous women $(n=764,56 \%)$. There were no exclusions on the basis of psycho-social, medical or obstetric reasons.

\section{Women with or without severe fear}

No differences were shown for demographic variables between women with severe fear (WDEQ $\geq 85$ ) and those without severe fear levels (W-DEQ <85). Refer Table 1. Severe fear was more frequent in nulliparous women compared to multiparous women $\left(x^{2}(1, n=1386)\right.$ $=4.9, \mathrm{p}=0.03$, phi $=-.06)$. There was no relationship between previous birth mode in multiparous women with or without severe levels of childbirth fear, however there was an $11 \%$ lower incidence of spontaneous vaginal birth for severely fearful women $(n=16,55.2 \%$ vs. $n=503,66.8 \%, p=0.24)$. Women's preference for mode of birth showed no difference between groups (refer to Table 1). While there was no relationship shown for parenting 
confidence, an association was found for all other psychosocial measures (EPDS, DCS, CBSEI) between women with severe levels of fear compared to women without severe fear scores (refer to Table 2).

\section{Comparison of women with high and severe fear}

There were no differences for demographic or obstetric variables (including parity) between women with high or severe levels of childbirth fear (Table 1). There was no difference between groups for parenting confidence; however the remaining psycho-social variables showed a significant difference for women with severe fear compared to women with high fear (refer to Table 2).

\section{Comparison of postnatal outcomes for women with high and severe childbirth fear}

Only women who returned data at $4-6$ weeks after birth could be analysed due to having participated in the primary randomised controlled study. In this analysis we compared women by their fear scores and not by randomised groups. There were 339 women randomised with 180 (53\%) returning postnatal data. There were no differences in respect of gestation at birth with the majority of women having a pregnancy continuing to term $(n=131$, $94.2 \%$ vs. $n=39,95.1 \%, p=N S)$. There were no differences between women with high or severe fear in respect of having a spontaneous birth or an operative delivery (forceps, vacuum, emergency or elective CS), epidural use for pain in labour, or in women's birth preference for a next pregnancy. However women with severe fear levels during pregnancy reported higher depressive symptoms after birth compared to women who had high childbirth fear scores in pregnancy. Following birth, 45 women had high fear, and 17 women had severe fear levels. There were no differences in fear levels between groups at 4 to 6 weeks postnatal (refer to Table 3).

\section{Predictors of childbirth fear}


In the first instance direct logistic regression was conducted for variables that demonstrated a significant difference (parity, EPDS, DCS, CBSEI) between groups for high and severe fear levels. We also drew on previous work where partner support and previous mode of birth for multiparous women were consistently reported as influencing fear levels ${ }^{4,11,16,31,39}$. We then repeated the logistic regression analysis inclusive of these additional variables in mulitparous women only.

In the initial regression analysis depressive symptoms, decisional conflict and anticipated low childbirth self-efficacy in second stage of labour were predictors for women with severe fear (W-DEQ $\geq 85$ ) compared to women with less fear (refer to Table 4). When W-DEQ $\geq 66$ scores were compared to lower scores these psychosocial predictors remained but also nulliparity and low childbirth self-efficacy for first stage of labour were predictors of fear (refer to Table 4).

For multiparous women the regression analysis was conducted for last birth compared with all the same variables as above. The EPDS, DCS, CBSEI second stage of labour remained significant between a W-DEQ cut point of $</ \geq 85$; however when tested against a W-DEQ cut point of $</ \geq 66$ a significant difference was also shown for having an unsupportive partner, operative vaginal birth $(p=.016$, OR 1.98, Cl1.139-3.462), and emergency CS $(p=$ $.008, \mathrm{OR} 2.92, \mathrm{Cl} 1.318-6.472)$ in the last birth (refer to Table 5).

\section{Discussion}

Given severe fear $(W-D E Q \geq 85)$ is now the level predominantly reported in the international literature, we felt it prudent to conduct a secondary analysis on data collected for the BELIEF study to determine if demographic, obstetric or psychosocial associations differed by fear level. 
We found no difference for demographic factors between high or severe levels of childbirth fear using a cut point score of W-DEQ 85. However associations between being in paid employment and a W-DEQ score of greater than 66 (which includes those women with severe levels of fear) have been previously reported ${ }^{4}$. Similarly a Finnish study also found women in higher paid employment were more likely to experience severe fear ${ }^{45}$. This high level of childbirth fear may be associated with wanting to be in control, concerns about financial stability due to an absence from paid employment, and impact of motherhood on career prospects. However, Swedish researchers found unemployment ${ }^{46}$ and employment ${ }^{7}$ to be associated with fear in pregnant women. These variations are not surprising given researchers have measured demographic variables in different ways and within different parity groups. Contrary to our findings, other studies have reported a relationship between severe childbirth fear and age ${ }^{3,11,45}$, education ${ }^{45-47}$, and smoking ${ }^{3,28,45}$ indicating possible broad variations between populations.

We found having a first baby did show a significant difference when women with severe fear levels were compared to the rest of the population. A difference in fear levels for nulliparous women is consistent with most other studies ${ }^{2,6,27}$ but contrary to recent Australian ${ }^{48}$ and Finnish work ${ }^{45}$. No difference for parity was shown when comparing high and severe score levels. We previously reported in this population that nulliparity was associated with high childbirth fear using a cut point of W-DEQ $\geq 66$; and now show here a significant difference for nulliparity using a cut point of $W-D E Q \geq 85$. This finding indicates that more nulliparous women have higher scores compared to multiparous women regardless of fear cut point level. However in their recent population based study of nearly 800,000 Finnish women, Raisanen et al. ${ }^{45}$ reported a 1.9 fold higher prevalence of fear in multiparous women but found a much lower prevalence of fear in their population overall compared to previous studies. The authors attributed this outcome to using the ICD-10 code 099.80 to detect childbirth fear. This may have inflated prevalence due to inclusion of broad categories of childbirth complicating factors. We found nulliparity was a predictor of high childbirth fear, 
however logistic regression analysis did not discriminate parity at the severe level indicating that high fear was sensitive to picking up this risk.

Our initial analysis of women with high childbirth fear in the BELIEF study reported a significant association between operative birth in a last pregnancy and high fear level in the current pregnancy ${ }^{4}$. Using a cut point of $\mathrm{W}$-DEQ $</ \geq 85$ revealed that women with severe fear have an $11 \%$ difference for experiencing an operative birth. Other studies have linked severe fear levels in multiparous women to a past history of operative birth ${ }^{24,40,49}$. Despite a clinical difference shown in women with severe levels of fear compared to the rest of the population, we found no significant differences when comparing groups at either the high or severe levels, indicating that operative birth influences both high and severe levels of childbirth fear similarly, but is sensitive to predicting childbirth fear in multiparous women at high fear levels.

Feelings of being excluded from decision-making, experiencing an operative birth, and more specifically, the experience of an emergency CS, are most frequently cited as provoking childbirth fear in a subsequent pregnancy and have been linked to the development of postnatal trauma symptoms ${ }^{25,50-54}$. Our logistic regression model showed that experiencing an operative vaginal birth, or emergency CS in the last birth, were predictors for childbirth fear scores at $\geq 66$ in the current pregnancy. There was no difference as a predictor at the severe level, once again indicating that in our Australian sample high childbirth fear levels were helpful for determining women who would benefit from support to address the negative short and longer term effects of fearful birth feelings. Furthermore women who had an operative vaginal birth had an odds ratio two times higher, and those who had an emergency CS had an odds ratio three times higher for developing childbirth fear when screened at W$D E Q \geq 66$. It would seem that screening women for severe levels of fear would miss identifing women with high fear who have a similar risk of an operative birth in their last pregnancy impacting this pregnancy. 
Emerging work on antenatal fear has linked increased cortisol levels in the mother to difficult labours, preterm birth, and predisposes the baby to cortisol reactivity over a lifetime with implications for childhood behavioural difficulties, anxiety and depressive illnesses ${ }^{55}$. Most commonly however, psychological and social indicators are associated with women developing childbirth fear ${ }^{1,3,29,31}$. Women who have a history of depression and / or anxiety consistently report childbirth fear ${ }^{1,56,57}$. Women who experience depression in the antenatal period are at higher risk of postnatal depression ${ }^{56,58}$, with recent findings in a Finnish sample showing childbirth fear alone predisposes women to developing postnatal depression ${ }^{56}$.

In regards to psychosocial measures, women in the current study reported significant differences when screened at both the high and severe levels of childbirth fear for depressive symptoms, higher decisional conflict and lower childbirth confidence. This may indicate that women reporting psycho-social distress have increasingly higher fear levels and are in need of more psychological support given that women in the severe fear group showed a significant likelihood of having depressive symptoms following birth. In the predictive model these psychosocial variables remained significant at both high and severe fear levels giving weight to the assertion that higher fear levels link to increasingly higher intensity of adverse psychological health markers.

Having an unsupportive partner is a significant indicator for childbirth fear when measured at the high fear level ${ }^{16}$, but no difference when high and severe fear levels were compared. This most likely indicates having a supportive partner is of equal importance regardless of fear level. This is consistent with previous work about fearful women ${ }^{3,28,31}$. In general, strong social support contributes to improved labour and birth outcomes and lower perinatal depression rates for the mother; and for the infant correlates with higher birth weight and Apgar scores ${ }^{59}$. In multiparous women, an unsupportive partner was predictive of high levels of fear. Not only is a woman's social network important but also the social context of 
her birth experience in respect of her relationship with maternity carers ${ }^{30,60}$ and the environment in which she births.

It was not surprising to find low levels of decision making and childbirth confidence (CBSEI) linked to high levels of childbirth fear. Lowe ${ }^{61}$ described the psycho-cultural environment of birth and its impact on women's self-efficacy. In our study of women in second trimester of pregnancy, low self-efficacy predicted high and severe levels of childbirth fear. Women's confidence plays a significant role in how they experience labour and birth. Women with low birth self-efficacy require not only emotional support, but opportunity to express concerns and be provided with education and strategies for how to build confidence and manage fear. 'Mothering the mother' is a term coined in the UK ${ }^{62}$ and highlights the nurturing aspect of care that women should receive as they prepare and adapt to becoming a new mother. The relationship principles of midwifery continuity of care provides for this through a focus on the bio-psychosocial aspects of the woman's life stage, and individualised communication which allows women time and space to be heard and understood ${ }^{63}$. Given midwifery continuity models are best practice ${ }^{64}$, ensuring all women have access to care by a known midwife may meet women's needs to manage their self-doubt and build resilience when experiencing childbirth fear. Having a trusted carer may also assist in early referral for women requiring additional psychological support given the relationship between childbirth fear and mental health difficulties $29,56,65$.

\section{Limitations}

Women with severe levels of childbirth fear accounted for $4.8 \%$ of our study population. This small incidence may have impacted on the likelihood of finding significant differences against the variables tested and therefore the findings must be regarded with caution. Additionally recruitment occurred in metropolitan south east Queensland with a maximum distance between hospitals of 70 kilometers. The findings may therefore not be generalised to the broader Australian population of birthing women. In respect of birth outcomes, only those 
women who returned data at $4-6$ weeks postnatal could be compared, therefore consideration needs to be given to possible differences between responders and nonresponders in the postnatal period. However these women had been randomised to the BELIEF study and it can be assumed that the groups were similar even though for the purposes of this paper data were not assessed within randomised groups.

Australian women experience high CS rates. The national rate is 32.3\%; and in Queensland $33.2 \%{ }^{66}$. Therefore finding no difference between operative and non-operative births for the current pregnancy or in respect of multiparous women in their previous birth by comparing high and severe fear levels, may not apply to countries with lower CS rates. However an operative vaginal birth or an emergency CS in the last birth was predictive of high childbirth fear this pregnancy.

Participation was inclusive of all birthing women who spoke and understood the English language. For that reason these findings may not apply to discrete groups such as nonEnglish speaking migrant populations and women with intellectual disability.

\section{Conclusion}

Australian women with high or severe levels of childbirth fear as measured on the W-DEQ have similar backgrounds and predictors for childbirth fear. Psychosocial indicators were significant at both the high and severe fear levels. At severe fear levels, mental health scores were more extreme, and screening women with a W-DEQ $\geq 85$ may identify women with underlying mental health problems that may be unrelated to, but exacerbated by, fears about the pregnancy and upcoming birth.

In the Australian context, identification of women with severe fear during pregnancy would likely prevent women with high levels of childbirth fear from receiving appropriate support. Due to different maternity models and cultural differences across countries, screening 
women should be adapted to local circumstances to reduce missed opportunities for identifying and supporting women's emotional wellbeing, preparation for birth, and subsequent experiences of birth. It is recommended, at least in the Australian context where CS has become a cultural norm, that women with high childbirth fear (W-DEQ $\geq 66$ ) should be identified and provided supportive measures to manage their fear and reduce avoidable CS . A sound strategy would be to offer a high level of primary carer support to improve these women's outcomes given the benefits of continuity of carer found for the general community of childbearing women.

\section{Acknowledgements}

The BELIEF study was funded by NHMRC (grant ID APP1025099).

\section{References}

1. Jokic-Begic N, Zigic L, Rados S. Anxiety and anxiety sensitivity as predictors of fear of different patterns for nulliparous and parous women. Journal of Psychosomatic Obstetrics \& Gynecology 2014; 35(1): 22-8.

2. Fenwick J, Gamble J, Nathan E, Bayes S, Hauck Y. Pre- and postpartum levels of childbirth fear and the relationship to birth outcomes in a cohort of Australian women. Journal of Clinical Nursing 2009; 18(667-677).

3. Laursen $\mathrm{M}$, Hedegaard $\mathrm{M}$, Johansen $\mathrm{C}$. Fear of childbirth: predictors and temporal changes among nulliparous women in the Danish National Birth Cohort. BJOG 2008; 115(3): 354-60.

4. Toohill J, Fenwick J, Gamble J, Creedy DK. Prevalence of childbirth fear in an Australian sample of pregnant women. BMC Pregnancy and Childbirth 2014; 14(275): DOI: 10.1186/471-239314-275.

5. Ryding E, Wirfelt E, Wangborg I, Sjogren B, Edman G. Personality and fear of childbirth. Acta Obstet Gyn Scan 2007; 68(7): 814-20.

6. Rouhe H, Salmela-Aro K, Halmesmaki E, Saisto T. Fear of childbirth according to parity, gestational age, and obstetric history. BJOG 2009; 116(1): 67-73.

7. Sydsjo G, Sydsjo A, Gunnervik C, Bladh M, Josefsson A. Obstetric outcome for women who received individualized treatment for fear of childbirth during pregnancy. Acta Obstetricia et Gynecologica Scandinavica 2012; 91(1): 44-9.

8. Wijma K, Wijma B, Zar M. Psychometric aspects of the W-DEQ; a new questionnaire for the measurement of fear of childbirth. Journal of Psychosomatic Obstetrics \& Gynecology 1998; 19(2): 84-97.

9. Zar M, Wijma K, Wijma B. Pre- and Postpartum Fear of Childbirth in Nulliparous and Parous Women. Scandinavian Journal of Behaviour Therapy 2001; 30(2): 75 - 84. 
10. Rouhe H, Salmela-Aro K, Toivanen R, Tokola M, Halmesmaki E, Saisto T. Obstetric outcome after intervention for severe fear of childbirth in nulliparous women - randomised trial. BJOG 2013; 120(1): 75-84.

11. Nieminen K, Stephansson O, Ryding EL. Women's fear of childbirth and preference for cesarean section - a cross-sectional study at various stages of pregnancy in Sweden. Acta Obstetricia et Gynecologica Scandinavica 2009; 88(7): 807-13.

12. Rubertsson C, Hellström J, Cross M, Sydsjö G. Anxiety in early pregnancy: prevalence and contributing factors. Archives of Women's Mental Health 2014; 17(3): 221-8.

13. Hall W, Hauck Y, Carty E, Hutton E, Fenwick J, Stoll K. Childbirth Fear, Anxiety, Fatigue, and Sleep Deprivation in Pregnant Women. JOGNN 2009; 38(5): 567-76.

14. Körükcü Ö, Fırat M, Kukulu K. Relationship between fear of childbirth and anxiety among Turkish pregnant women. Procedia - Social and Behavioral Sciences 2010; 5: 467-70.

15. Matthey S, Ross-Hamid C. Repeat testing on the Edinburgh Depression Scale and the HADS-A in pregnancy: Differentiating between transient and enduring distress. Journal of Affective Disorders 2012; 141: 213-21.

16. Toohill J, Fenwick J, Gamble J, Creedy DK, Buist A, Ryding EL. Psycho-Social Predictors of Childbirth Fear in Pregnant Women: An Australian Study. Open Journal of Obstetrics and Gynecology 2014; 4(9): 531-43. http://dx.doi.org/10.4236/ojog.2014.49075

17. Fenwick J, Toohill J, Creedy D, Smith J, Gamble J. Sources, responses and moderators of childbirth fear in Australian women: a qualitative investigation Midwifery 2015; 31: 239-46.

18. Hofberg K, Ward M. Fear of Childbirth, Tocophobia, and mental health in Mothers: The Obstetric-Psychiatric Interface. Clinical Obstetrics and Gynecology 2004; 47(3): 527-34.

19. Fenwick J, Gamble J, Creedy D, et al. Study protocol for reducing childbirth fear: a midwifeled psycho-education intervention. BMC Pregnancy and Childbirth; 2013. p. DOI:10.1186/471-239313-190.

20. Toohill J, Fenwick J, Gamble J, Creedy D, Buist A, Ryding A. A randomized controlled trial of a psycho-education intervention by midwives in reducing childbirth fear in pregnant women. Birth 2014; 41(4): 384-94.

21. Adams S, Eberhard-Gran M, Eskild A. Fear of childbirth and duration of labour: a study of 2206 women with intended vaginal delivery. BJOG; DOI:101111/j1471-0528201203433x 2012.

22. Lukasse M, Schei B, Ryding A. Prevalence and associated factors of fear of childbirth in six European countries. Sexual \& Reproductive Healthcare 2014; 5(3 ): 99 - 106. doi:

10.1016/j.srhc.2014.06.007.

23. Ryding E, Wijma K, Wijma B. Psychological impact of emergency Cesarean section in comparison with elective Cesarean section, instrumental and normal vaginal delivery. Journal of Psychosomatic Obstetrics \& Gynecology 1998; 19(3): 135-44.

24. Nilsson C, Lundgren I, Karlstrom A, Hildingsson I. Self reported fear of childbirth and its association with women's birth experience and mode of delivery: A longitudinal population-based study. Women and Birth 2012; 25(3): 114-21.

25. Ryding E, Wijma K, Wijma B. Postpartum counselling after an emergency cesarean. Clinical Psychology \& Psychotherapy 1998; 5(4): 231-7.

26. Kjaergaard H, Wijma K, Dykes A, Alehagen S. Fear of childbirth in obstetrically low-risk nulliparous women in Sweden \& Denmark. J Reprod Infant Psyc 2008; 26(4): 340-50.

27. Johnson $\mathrm{R}$, Slade P. Does fear of childbirth during pregnancy predict emergency caesarean section? BJOG 2002; 109(11): 1213-21.

28. Waldenstrom $U$, Hildingsson I, Ryding E. Antenatal fear of childbirth and its association with subsequent caesarean section and experience of childbirth. BJOG 2006; 113(6): 638-46.

29. Rouhe H, Salmela-Aro K, Gissler M, Halmesmaki E, Saisto T. Mental health problems common in women with fear of childbirth. BJOG 2011; 118(9): 1104-11.

30. Fisher $\mathrm{C}$, Hauck $\mathrm{Y}$, Fenwick J. How social context impacts on women's fears of childbirth: A Western Australian example. Social Science \& Medicine 2006; 63(1): 64-75. 
31. Saisto T, Salmela-Aro K, Nurmi J, Halmesmaki E. Psychosocial characteristics of women and their partners fearing vaginal childbirth. BJOG 2001; 108(5): 492-8.

32. Halvorsen L, Nerum H, Sorlie T, Oian P. Does counsellor's attitude influence change in a request for a caesarean in women with fear of birth? Midwifery 2010; 26 45-52.

33. Saisto T, Salmela-Aro K, Nurmi J, Kononen T, Halmesmaki E. A randomized controlled trial of intervention in fear of childbirth. Obstetrics and Gynecology 2001; 98(5): 820-6.

34. Salmela-Aro K, Read S, Rouhe $\mathrm{H}$, et al. Promoting positive motherhood among nulliparous pregnant women with an intense fear of childbirth: RCT intervention. Journal of Health Psychology 2012; 17(4): 520-34.

35. Sjogren B, Thomassen P. Obstetric outcome in 100 women with severe anxiety over childbirth. Acta Obstet Gynecol Scand 1997; 76: 948-52.

36. Saisto T, Halmesmaki E. Fear of childbirth: a neglected dilemma. Acta Obstet Gynecol Scand 2003; 82: 201-8.

37. D'Souza R. Caesarean section on maternal request for non-medical reasons: Putting the UK National Institute of Health and Clinical Excellence guidelines in perspective. Best Practice \& Research Clinical Obstetrics \& Gynaecology 2013; 27(2): 165-77.

38. Ryding E, Wijma B, Wijma K, Rydhstrom $\mathrm{H}$. Fear of childbirth during pregnancy may increase the risk of emergency cesarean section. Acta Obstet Gynecol Scand 1998; 77: 542-7.

39. Ryding E, Lukasse M, Schei B. Fear of childbirth - does it affect mode of delivery. The BIDENS study - results from six countries. Acta Obstetricia et Gynecologica Scandinavica 2012; 91: 38.

40. Laursen $M$, Johansen $C$, Hedegaard $M$. Fear of childbirth and risk for birth complications in nulliparous women in the Danish National Birth Cohort. BJOG: An International Journal of Obstetrics \& Gynaecology 2009; 116(10): 1350-5.

41. Geissbuehler V, Eberhard J. Fear of childbirth during pregnancy: A study of more than 8000 pregnant women. Journal of Psychosomatic Obstetrics \& Gynecology 2002; 23(4): 229-35.

42. Wiklund I, Andolf E, Lilja H, Hildingsson I. Indications for cesarean section on maternal request - Guidelines for counseling and treatment. Sexual \& Reproductive Healthcare 2012; 3: 99106.

43. Saisto T, Toivanen R, Salmela-Aro K, Halmesmaki E. Therapeutic group psychoeducation and relaxation in treating fear of childbirth. Acta Obstetricia et Gynecologica Scandinavica 2006; 85(11): 1315-9.

44. IBM Corp. IBM SPSS Statistics for Windows, Version 21.0. Armonk, NY: IBM Corp. 2012.

45. Räisänen S, Lehto SM, Nielsen HS, Gissler M, Kramer MR, Heinonen S. Fear of childbirth in nulliparous and multiparous women: a population-based analysis of all singleton births in Finland in 1997-2010. BJOG: An International Journal of Obstetrics \& Gynaecology 2014; 121(8): 965-70.

46. Salomonsson B, Bertero C, Alehagen S. Self-Efficacy in Pregnant Women with Severe Fear of Childbirth. JOGNN 2013; 42(2): 191-202.

47. Melender H-L. Experiences of Fears Associated with Pregnancy and Childbirth: A Study of 329 Pregnant Women. Birth 2002; 29(2): 101-11.

48. Haines H, Pallant J, Karlstrom A, Hildingsson I. Cross-cultural comparison of levels of childbirth-related fear in an Australian and Swedish sample. Midwifery 2011; 27(4): 560-7.

49. Saisto T, Ylikorkala O, Halmesmaki E. Factors associated with fear of delivery in second pregnancies. Obstet Gynecol 1999; 94: 679-82.

50. Nilsson C, Bondas T, Lundgren I. Previous Birth Experience in Women With Intense Fear of Childbirth. Journal of Obstetric, Gynecologic, \& Neonatal Nursing 2010; 39(3): 298-309.

51. Ryding E, Wijma B, Wijma K. Posttraumatic stress reactions after emergency cesarean section. Acta Obstet Gynecol Scand 1997; 76(856-861).

52. Soet J, Brack G, Dilorio C. Prevalence and predictors of women's experience of psychological trauma during childbirth. Birth 2003; 30(1): 36-46.

53. Creedy D, Shochet I, Horsfall J. Childbirth and the Development of Acute Trauma Symptoms: Incidence and Contributing Factors. Birth 2000; 27(2): 104-11. 
54. Boorman R, Devilly G, Gamble J, Creedy DK, Fenwick J. Childbirth and criteria for traumatic events. Midwifery 2014; 30(2): 255-61.

55. Tollenaar M, Beijers R, Jansen J, Riksen-Walraven J, de Weerth C. Maternal prenatal stress and cortisol reactivity to stressors in human infants. Stress 2011; 14 (1): 53-65.

56. Raisanen S, Lehto S, Nielsen H, Gissler M, Kramer M, Heinonen S. Fear of childbirth predicts postpartum depression: a population-based analysis of 511422 singleton births in Finland. BMJ Open 2013; 3:e004047. doi:10.1136/bmjopen-2013-004047.

57. Zar M, Wijma K, Wijma B. Relations between anxiety disorders and fear of childbirth during late pregnancy. Clinical Psychology \& Psychotherapy 2002; 9(2): 122-30.

58. Milgrom J, Gemmill A, Bilszta J, et al. Antenatal risk factors for postnatal depression: a large prospective study. J Affect Disord 2008; 108(1-2): 147-57.

59. Collins N, Dunkel-Schetter C, Lobel M, Scrimshaw S. Social support in pregnancy:

Psychosocial correlates of birth outcomes and postpartum depression. Journal of Personality and Social Psychology 1993; 65(6): 1243-58.

60. Oakley A, Rajan L, Grant A. Social support and pregnancy outcome. International Journal of Gynecology \& Obstetrics 1990; 33(4): 385-6.

61. Lowe N. Self-efficacy for labor and childbirth fears in nulliparous pregnant women. Journal of Psychosomatic Obstetrics \& Gynecology 2000; 21(4): 219-24.

62. Wlash D, Newburn M. Towards a social model of childbirth: part two. British Journal of Midwifery 2002; 10(9): 540-4.

63. Matthias M. Problematic Integration in Pregnancy and Childbirth: Contrasting Approaches to Uncertainty and Desire in Obstetric and Midwifery Care Health Communication 2009; 24(1): 60 70.

64. Hatem M, Sandall J, Devane D, Soltani H, Gates S. Midwife-led versus other models of care for childbearing women. Cochrane Database of Systematic Reviews, Issue 4. Art. No.: CD004667. DOI: 10.1002/14651858.CD004667.pub2. 2008.

65. Storksen H, Eberhard-Gran M, Garthus-Niegel S, Eskild A. Fear of childbirth; the relation to anxiety and depression. Acta Obstetricia et Gynecologica Scandinavica 2012; 91: 237-42.

66. Li Z, Zeki R, Hilder L, Sullivan E. Australia's mothers and babies 2011. Perinatal statistics series no. 28. Cat. no. PER 59. Canberra: AIHW. 2013.

67. Cox J, Holden J, Sagousky R. Detection of postnatal depression development of the 10 item Edinburgh Depression Scale. BMJ 1987; 150: 782-6.

68. Lowe NK. Maternal confidence for labour: Development of the Childbirth Self-Efficacy Inventory. Res Nurs Health 1993; 16(2): 141-9.

69. Drummond J, Rickwood D. Childbirth confidence: validating the childbirth self-efficacy inventory (CBSEI) in an Australian sample. Journal of Advanced Nursing 1997; 26(3): 613-22.

70. Shorten A, et al. Making choices for childbirth: A randomised controlled trial of a decisionaid for informed birth after cesarean. Birth 2005; 32(4): 252-61.

71. O'Connor A. User Manual - Decisional Conflict Scale [internet]. 1993 [Updated 2010; cited 01/02/11]. Available from

http://decisionaid.ohri.ca/docs/develop/User Manuals/UM Decisional Conflict.pdf.

72. Johnston C, Mash E. A measure of parenting satisfaction and efficacy. J Clin Child Psychol 1989; 18: 167-75. 


\section{Box 1 Psychosocial Measures}

\begin{tabular}{|c|c|}
\hline $\begin{array}{l}\text { Edinburgh Postnatal } \\
\text { Depression Scale }\end{array}$ & $\begin{array}{l}10 \text { item well validated self-report questionnaire designed to screen } \\
\text { for depression. It has a split-half reliability of } 0.88 \text { and } \\
\text { standardised alpha coefficient of } 0.87 \text {. Range of scores is from 0- } \\
30 \text { with postnatal scores above } 12 \text { indicative of probable } \\
\text { depression }{ }^{67} \text {. Cronbach alpha in this study was } 0.86 \text {. }\end{array}$ \\
\hline $\begin{array}{l}\text { Wijma Delivery } \\
\text { Expectancy/Experience } \\
\text { Questionnaire } \\
(W-D E Q)\end{array}$ & $\begin{array}{l}\text { 33-item, 6-point Likert scale questionnaire that measures women's } \\
\text { fear of childbirth. Items refer to expectations and experiences } \\
\text { before birth (version A) and after birth (version B). It has good } \\
\text { internal consistency and split-half reliability (>0.94 before and }> \\
0.87 \text { after birth) with nulliparous and multiparous women }{ }^{8,9} \text {. In this } \\
\text { study the Cronbach alpha was } 0.94 \text {. }\end{array}$ \\
\hline $\begin{array}{l}\text { Childbirth Self-Efficacy } \\
\text { Inventory (CBSEI) }\end{array}$ & $\begin{array}{l}\text { 62-item scale }{ }^{68} \text { that requires responses on a 10-point Likert scale. } \\
\text { Has four components to capture the specific beliefs and } \\
\text { behaviours during the first and second stage of labour. High } \\
\text { scores indicate high self-efficacy or outcome expectancy for birth. } \\
\text { The CBSEI has been validated for use in the Australian birthing } \\
\text { population }{ }^{69} \text {. In this study the Cronbach alpha was above } 0.90 \text { for } \\
\text { all four subscales. }\end{array}$ \\
\hline $\begin{array}{l}\text { Decisional Conflict } \\
\text { Scale (DCS) }\end{array}$ & $\begin{array}{l}16 \text { item scale, which investigates factors that compromise or } \\
\text { facilitate effective decision making. Has been used in decision aid } \\
\text { research (including VBAC) within the Australian context }{ }^{70} \text {. Internal } \\
\text { consistency coefficients ranged from } 0.78 \text { to } 0.92 \text { and } \\
\text { discriminated significantly ( } p<0.001 \text { ) between those who had } \\
\text { strong intentions either to accept or decline a method of care } \\
\text { compared to those who were uncertain }{ }^{71} \text {. The Cronbach alpha in } \\
\text { this study was } 0.97 \text {. }\end{array}$ \\
\hline
\end{tabular}


Parenting Sense of

Confidence and

Satisfaction

(PSOC - 12 items)
Measures self-efficacy and satisfaction derived from parenting ${ }^{72}$.

Only the self-efficacy factor (7 items, 6-point Likert scale) was used. This factor has good internal consistency ( $\alpha$.76) with higher scores indicating stronger self-efficacy, with a Cronbach alpha of 0.91 in this study. 
Table 1 Demographic and obstetric comparisons for women with different fear levels in second trimester of pregnancy ( $W$-DEQ $<85$ and $\geq 85$; W-DEQ $\geq 66$ and $\geq 85$ )

\begin{tabular}{|c|c|c|c|c|c|}
\hline & $\begin{array}{l}p- \\
\text { value }\end{array}$ & $\begin{array}{l}\text { W-DEQ 0-84 } \\
n=1318(\%)\end{array}$ & $\begin{array}{l}W-D E Q \geq 85 \\
n=68(\%)\end{array}$ & $\begin{array}{l}\text { W-DEQ 66-84 } \\
n=265(\%)\end{array}$ & $\begin{array}{l}p- \\
\text { value }\end{array}$ \\
\hline Australian Born & 0.95 & $973(73.9)$ & $51(75.0)$ & $193(72.8)$ & 0.84 \\
\hline $\begin{array}{l}\text { Age } \\
\text { (Mean, SD, Range) }\end{array}$ & 0.82 & $\begin{array}{l}28.8 \\
(5.5,17-51)\end{array}$ & $\begin{array}{l}28.8 \\
(5.6,17-42)\end{array}$ & $\begin{array}{l}28.5 \\
(5.6,17-51)\end{array}$ & 0.66 \\
\hline $\begin{array}{l}\text { Income }<\$ 78,000 \\
\text { per annum }\end{array}$ & 0.62 & 738 (59.1) & $37(55.2)$ & $156(61.4)$ & 0.43 \\
\hline $\begin{array}{l}\text { No paid } \\
\text { Employment }\end{array}$ & 0.54 & $425(32.4)$ & $25(36.8)$ & $80(30.2)$ & 0.37 \\
\hline $\begin{array}{l}\text { Pregnancy } \\
\text { unplanned }\end{array}$ & 0.21 & $455(34.5)$ & $29(42.6)$ & $104(39.2)$ & 0.71 \\
\hline $\begin{array}{l}\text { BMI } \\
\text { (Mean, SD, Range) }\end{array}$ & 1.00 & $\begin{array}{l}26.6 \\
(6.2,13-78)\end{array}$ & $\begin{array}{l}26.5 \\
(5.1,19-47)\end{array}$ & $\begin{array}{l}26.5 \\
(5.8,17-53)\end{array}$ & 1.00 \\
\hline $\begin{array}{l}\text { Post high school } \\
\text { education }\end{array}$ & 0.17 & $651(49.4)$ & $40(58.8)$ & $130(49.1)$ & 0.19 \\
\hline $\begin{array}{l}\text { Smoking at } 36 \\
\text { weeks }\end{array}$ & 0.67 & $11(0.9)$ & $2(3.0)$ & $11(4.8)$ & 0.67 \\
\hline $\begin{array}{l}\text { Unsupportive } \\
\text { partner }\end{array}$ & 0.13 & $55(4.2)$ & $6(9.0)$ & $25(9.6)$ & 1.00 \\
\hline Living with partner & 0.09 & $1060(80.8)$ & $61(89.7)$ & 207 (78.1) & 0.48 \\
\hline $\begin{array}{l}\text { Moderate to severe } \\
\text { pain } 2^{\text {nd }} \text { trimester }\end{array}$ & 0.08 & $471(35.8)$ & $32(47.1)$ & $118(44.5)$ & 0.81 \\
\hline $\begin{array}{l}\text { Less birth } \\
\text { knowledge }\end{array}$ & 0.72 & $1006(76.8)$ & $54(79.4)$ & $216(81.8)$ & 0.78 \\
\hline Gestation (Mean, & 0.74 & $18.6(2.9$ & $18.5(3.5$ & $18.4(2.9$ & 0.90 \\
\hline
\end{tabular}




\begin{tabular}{llllll}
\hline SD, Range) & \multicolumn{1}{l}{$11-25)$} & $11-25)$ & $11-24)$ & 1.00 \\
$\begin{array}{l}\text { Parity } \\
\text { Nulliparous }\end{array}$ & & $565(42.9)$ & $39(57.4)$ & $151(57.0)$ & \\
$\begin{array}{l}\text { Multiparous } \\
\text { Last mode of birth }\end{array}$ & 0.24 & $753(57.1)$ & $29(42.6)$ & $114(43.0)$ & \\
$\begin{array}{l}\text { Vaginal non- } \\
\text { instrument }\end{array}$ & & $503(66.8)$ & $16(55.2)$ & $60(53.1)$ & \\
$\begin{array}{l}\text { Any operative birth } \\
\text { Missing }\end{array}$ & $243(32.3)$ & $13(44.8)$ & $53(46.9)$ & \\
Prefer CS delivery & 0.61 & $143(11.0)$ & $9(13.8)$ & $42(16.0)$ & 0.80 \\
\hline
\end{tabular}


Table 2 Psycho-social comparisons for women with different fear levels in second trimester of pregnancy (W-DEQ $<85$ and $\geq 85$; $W$-DEQ $\geq 66$ and $\geq 85$ )

\begin{tabular}{|c|c|c|c|c|c|}
\hline & $\begin{array}{l}p- \\
\text { value }\end{array}$ & $\begin{array}{l}\text { W-DEQ 0-84 } \\
n=1318\end{array}$ & $\begin{array}{l}\text { W-DEQ } \geq 85 \\
n=68\end{array}$ & $\begin{array}{l}\text { W-DEQ 66-84 } \\
n=265\end{array}$ & $\begin{array}{l}\mathrm{p}- \\
\text { value }\end{array}$ \\
\hline $\begin{array}{l}\text { WDEQ (Mean, SD, } \\
\text { Range) }\end{array}$ & $<.001$ & $\begin{array}{l}47.0(19.4,0- \\
84)\end{array}$ & $\begin{array}{l}96.9(11.0, \\
85-128)\end{array}$ & $\begin{array}{l}73.3(4.9, \\
66-84)\end{array}$ & $<.001$ \\
\hline $\begin{array}{l}\text { EPDS (Mean, SD, } \\
\text { Range) }\end{array}$ & $<.001$ & $\begin{array}{l}4.9(4.4 \\
0-24)\end{array}$ & $\begin{array}{l}9.8(5.7, \\
0-21)\end{array}$ & $\begin{array}{l}7.4(5.1 \\
0-24)\end{array}$ & 0.002 \\
\hline $\begin{array}{l}\text { Anxiety Sub-scale } \\
\text { (Mean, SD, Range) }\end{array}$ & $<.001$ & $2.4(2.1,0-9)$ & $4.3(2,0-8)$ & $3.4(2.2,0-9)$ & 0.002 \\
\hline $\begin{array}{l}\text { DCS (Mean, SD, } \\
\text { Range) }\end{array}$ & $<.001$ & $\begin{array}{l}28.7(22.5,0- \\
100)\end{array}$ & $\begin{array}{l}50.4,23.3,0- \\
100)\end{array}$ & $\begin{array}{l}38.2(21.9,0- \\
100)\end{array}$ & $<.001$ \\
\hline $\begin{array}{l}\text { CBSEl(Mean, SD, } \\
\text { Range) }\end{array}$ & & & & & \\
\hline $\begin{array}{l}\text { Outcome active } \\
\text { labour }\end{array}$ & $<.001$ & $\begin{array}{l}114.5(24.5 \\
15-150)\end{array}$ & $\begin{array}{l}90.6(34.1, \\
15-150)\end{array}$ & $\begin{array}{l}105.3(27.9 \\
15-150)\end{array}$ & $<.001$ \\
\hline $\begin{array}{l}\text { Self-efficacy active } \\
\text { labour }\end{array}$ & $<.001$ & $\begin{array}{l}105.1(29.2, \\
15-150)\end{array}$ & $\begin{array}{l}70.9(33.3, \\
15-150)\end{array}$ & $\begin{array}{l}87.5(30.7 \\
15-150)\end{array}$ & $<.001$ \\
\hline $\begin{array}{l}\text { Outcome second } \\
\text { stage }\end{array}$ & $<.001$ & $\begin{array}{l}118.5(30.7, \\
16-160)\end{array}$ & $\begin{array}{l}81.7(39.8, \\
16-160)\end{array}$ & $\begin{array}{l}103.8(35.0 \\
16-160)\end{array}$ & $<.001$ \\
\hline $\begin{array}{l}\text { Self-efficacy second } \\
\text { stage }\end{array}$ & $<.001$ & $\begin{array}{l}111.1(33.7 \\
16-160)\end{array}$ & $\begin{array}{l}67.3(36.6, \\
16-160)\end{array}$ & $\begin{array}{l}91.5(36.7 \\
16-160)\end{array}$ & $<.001$ \\
\hline $\begin{array}{l}\text { PSOC (Mean, SD, } \\
\text { Range) }\end{array}$ & 0.09 & $\begin{array}{l}34.7(6.3 \\
7-42)\end{array}$ & $\begin{array}{l}33.4(5.4,22- \\
42)\end{array}$ & $\begin{array}{l}32.6(6.3,10- \\
42)\end{array}$ & 0.65 \\
\hline
\end{tabular}


Table 3 Differences for women with high and severe level antenatal W-DEQ scores following birth

\begin{tabular}{|c|c|c|c|}
\hline & $\begin{array}{l}\text { W-DEQ 66-84 } \\
n=139 *(\%)\end{array}$ & $\begin{array}{l}\text { W-DEQ } \geq 85 \\
n=41 *(\%)\end{array}$ & $p$ - value \\
\hline Term Birth & $131(94.2)$ & $39(95.1)$ & 1.00 \\
\hline $\begin{array}{l}\text { Gestation (Mean, SD, } \\
\text { Range) }\end{array}$ & $39.1(2.0,28-42)$ & $39.3(1.3,36-41)$ & \\
\hline Mode of Birth & & & 0.95 \\
\hline Vaginal non- & $64(46.0)$ & $18(43.9)$ & \\
\hline instrument & $75(54.0)$ & 23 (56.1) & \\
\hline Any operative birth & & & \\
\hline Prefer CS next birth & $33(23.9)$ & $8(19.5)$ & 0.95 \\
\hline Epidural in labour & $50(41.0)$ & $15(44.1)$ & 0.90 \\
\hline W-DEQB (Mean, SD, & 59.7 (21.3, & $64.2(26.7$ & 0.55 \\
\hline Range) & 16-122) & $15-129)$ & \\
\hline EPDS & $5.4(5.0,0-23)$ & & \\
\hline (Mean, SD, Range) & & $7.0(4.2,1-16)$ & 0.02 \\
\hline Anxiety Sub-scale & $2.4(2.2,0-8)$ & & \\
\hline (Mean, SD, Range) & & $3.1(2.2,0-8)$ & 0.07 \\
\hline PSOC (Mean, SD, & $33.1(6.5,10-42)$ & $31.8(6.5$ & 0.22 \\
\hline Range) & & 18-41) & \\
\hline
\end{tabular}

* Data at 4-6 weeks postnatal were women who met BELIEF study randomisation criteria and returned data (high fear: $n=139 / 265,52 \%$ and severe fear $n=41 / 68,60 \%$ ). 
Table 4 Logistic regression analysis for high and severe levels of fear

\begin{tabular}{|c|c|c|c|}
\hline Predictor Variable & B & Odds Ratio (95\% Cl) & $p$ - value \\
\hline \multicolumn{4}{|l|}{ WDEQ $<66$ and $\geq 66$} \\
\hline Parity & -.421 & $.657(.482-.895)$ & .008 \\
\hline EPDS & .128 & $1.137(1.101-1.174)$ & $<.001$ \\
\hline DCS & .020 & $1.020(1.013-1.027)$ & $<.001$ \\
\hline CBSEI Outcome Active Labour & -.006 & $1.006(.996-1.016)$ & .246 \\
\hline CBSEI Self Efficacy Active & -.012 & $.988(.978-.997)$ & .014 \\
\hline \multicolumn{4}{|l|}{ Labour } \\
\hline CBSEI Outcome Second Stage & -.007 & $.993(.984-1.002)$ & .132 \\
\hline CBSEI Self Efficacy Second & -.009 & $.991(.982-1.000)$ & .038 \\
\hline \multicolumn{4}{|l|}{ Stage } \\
\hline Unsupportive Partner & -1.115 & $.328(.170-.633)$ & .001 \\
\hline \multicolumn{4}{|l|}{ WDEQ $<84$ and $\geq 85$} \\
\hline Predictor Variable & B & Odds Ratio (95\% Cl) & $p$ - value \\
\hline Parity & -.090 & $0.914(.492-1.698)$ & .775 \\
\hline EPDS & .116 & $1.123(1.066-1.183)$ & $<.001$ \\
\hline DCS & .029 & $1.029(1.016-1.042)$ & $<.001$ \\
\hline CBSEI Outcome Active Labour & -.010 & $0.990(.974-1.007)$ & .245 \\
\hline CBSEI Self Efficacy Active & -.003 & $1.003(.985-1.021)$ & .759 \\
\hline \multicolumn{4}{|l|}{ Labour } \\
\hline CBSEI Outcome Second Stage & -.004 & $0.996(.982-1.010)$ & .561 \\
\hline CBSEI Self Efficacy Second & -.020 & $0.980(.965-.995)$ & .011 \\
\hline \multicolumn{4}{|l|}{ Stage } \\
\hline Unsupportive Partner & -.030 & $0.971(.319-2.951)$ & .958 \\
\hline
\end{tabular}


Table 5 Logistic regression analysis for multiparous women with high and severe levels of fear

\begin{tabular}{|c|c|c|c|}
\hline Predictor Variable & B & Odds Ratio (95\% Cl) & $p$ - value \\
\hline \multicolumn{4}{|l|}{ WDEQ $<66$ and $\geq 66$} \\
\hline \multicolumn{4}{|l|}{ Last mode of birth: } \\
\hline SVD & .331 & $1.393(.699-2.777)$ & .346 \\
\hline Operative vaginal & .686 & 1.986 (1.139- 3.462) & .016 \\
\hline Emergency CS & 1.072 & 2.920 (1.318- 6.472) & .008 \\
\hline Elective CS & .265 & $1.303(.140-12.091)$ & .816 \\
\hline EPDS & .112 & 1.119 (1.070- 1.170) & $<.001$ \\
\hline DCS & .020 & $1.021(1.011-1.030)$ & $<.001$ \\
\hline CBSEI Outcome Active Labour & -.008 & 1.008 (.994- 1.022) & .290 \\
\hline CBSEI Self Efficacy Active & -.012 & $.988 .974-1.002)$ & .083 \\
\hline \multicolumn{4}{|l|}{ Labour } \\
\hline CBSEI Outcome Second Stage & -.003 & $.997(.984-1.011)$ & .702 \\
\hline CBSEI Self Efficacy Second & -.016 & $.984(.971-.996$ & .012 \\
\hline \multicolumn{4}{|l|}{ Stage } \\
\hline Unsupportive Partner & -1.322 & $.267(.106-.671)$ & .005 \\
\hline \multicolumn{4}{|l|}{ WDEQ $<85$ and $\geq 85$} \\
\hline Predictor Variable & B & Odds Ratio (95\% Cl) & $p$ - value \\
\hline \multicolumn{4}{|l|}{ Last mode of birth: } \\
\hline SVD & -.196 & $.822(.171-3.962)$ & .807 \\
\hline Operative vaginal & .387 & $1.473(.501-4.327)$ & .481 \\
\hline Emergency CS & .288 & $1.334(.252-7.064)$ & .734 \\
\hline Elective CS & -17.341 & $.000(.000)$ & .999 \\
\hline
\end{tabular}




\begin{tabular}{llcc}
\hline EPDS & .103 & $1.108(1.025-1.198)$ & .010 \\
DCS & .025 & $1.025(1.006-1.044)$ & .008 \\
CBSEI Outcome Active Labour & -.016 & $.985(.959-1.011)$ & .245 \\
CBSEI Self Efficacy Active & -.002 & $.998(.971-1.026)$ & .902 \\
Labour & & $1.004(.981-1.028)$ & .714 \\
CBSEI Outcome Second Stage & -.004 & $.976(.953-.998)$ & .034 \\
CBSEI Self Efficacy Second & -.025 & & .393 \\
Stage & & $2.690(.278-26.042)$ & \\
Unsupportive Partner & .989 & & \\
\hline
\end{tabular}

